\title{
The importance of preoperative elevated serum levels of CEA and CA15-3 in patients with breast cancer in predicting its histological type
}

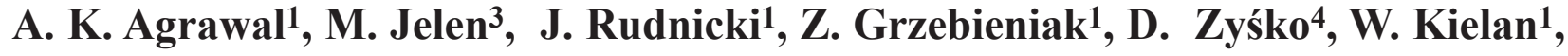 \\ J. Słonina ${ }^{2}$, G. Marek ${ }^{1}$
}

12nd Department of General and Oncological Surgery, Wroclaw Medical University, Wroclaw, Poland

2Department of Radiology, Wroclaw Medical University, Wroclaw, Poland

${ }^{3}$ Department of Pathology, Wroclaw Medical University, Wroclaw, Poland

${ }^{4}$ Teaching Department for Emergency Medical Services, Wroclaw Medical University, Wroclaw, Poland

\begin{abstract}
It is not known whether in patients with breast cancer the occurrence of elevated serum tumour markers depends on its histological type. The aim of the study was to assess relationship between breast cancer histological type and the presence of increased serum levels of CEA and CA 15-3. The study population was 428 patients (all women, mean age 52.5 years), treated at The Department of Surgery of Wroclaw Medical University from 2005 to 2008 due to breast cancer. All of them had their preoperative CA 15-3 and CEA serum concentrations measured. According to the TNM system, $21 \%$ of patients were in stage I, $32.5 \%$ in stage II, $46.5 \%$ in stage III of the disease. In patients with ductal type of the cancer the elevated serum levels of CEA and CA $15-3$ were observed in 48.7\% and 42.2\%, in lobular type in $42.4 \%$ and $52.5 \%$, and in non-ductal/tubular types in $48.1 \%$ and $40.4 \%(\mathrm{p}=\mathrm{N} / \mathrm{S})$. Stepwise logistic regression analyses showed that ductal breast cancer is related to elevated CEA and normal CA 15-3 serum levels. The histological types of breast cancer are not significantly related to elevated serum levels of CEA and/or CA 15-3.
\end{abstract}

Key words: breast cancer, serum tumour marker, CA 15-3, CEA, histological type

\section{Introduction}

For many malignancies, serum tumour markers play an important role in patient management. In breast cancer the role of serum markers is less well established [13]. The elevation of serum markers in breast cancer may be helpful in early diagnosis, determining prognosis, predicting response or resistance to specific therapies, surveillance after primary surgery, and monitoring therapy in patients with advanced disease [4-6]. Breast cancer is a heterogenic disease and none of the available markers is increased in all patients with breast cancer even in an advanced stage of the disease [2,4]. It is not known whether the presence of increased preoperative level of the most widely used markers as CA 15-3 and CEA depends on the histological type of the breast cancer.

Correspondence: A.K. Agrawal, 2nd Department of General and Oncological Surgery, Wroclaw Medical University, Borowska Str. 213, 50-556 Wroclaw, Poland; tel.: (+48) 609289027, fax.: (+4871) 7828834, e-mail: dranilpreeti@gmail.com
The aim of the study was to assess the relationship between histological type of the breast cancer and the presence of the increased serum levels of breast cancer markers like CEA and/or CA 15-3.

\section{Material and methods}

Tumour samples. A total of 428 patients were treated at The Department of Surgery of Wroclaw Medical University from 2005 to 2008 due to the diagnosis of breast cancer. All of them had their preoperative CA 15-3 and CEA serum concentrations measured. In all patients tumours were invasive cancers in stages I-III, and the mean age of patients was 52.5 years (range $24-83$ years). All the patients in the study were women and $54.5 \%$ of them were postmenopausal.

Tumour markers. Studied tumour markers levels were measured by immunoassays: Enzymum test 300 using the cutoff value of 5 $\mathrm{ng} / \mathrm{ml}$ for CEA and Enzymum-test CA 15-3 using the cutoff value of 40 units $/ \mathrm{ml}$ for CA 15.3. Intra- and interassay variations for both markers were $5 \%$ and $10 \%$, respectively. Measurements of serum concentrations of CEA and CA 15-3 were blinded. In all cases histological slides from paraffin wax embedded material 
were critically reviewed and classified according to the criteria of WHO [7].

Statistical analysis. The frequency of occurrence of the elevated serum levels of CEA and CA 15-3 tumour markers were calculated for the whole population and for the groups according to the disease stage assessed according to the TNM system and histological types of the carcinomas. The differences between these frequencies were compared using $\mathrm{Ch} 2$ test. Taking into account that ductal cancer malignancy was the most common type, the patients were dichotomized according to its presence or absence. The logistic regression analysis was performed to assess the relationship between ductal type of breast cancer and the presence of the CEA and CA 15-3 elevation in the serum of these patients and the stage of the disease. P less than 0.05 was regarded as significant.

\section{Results}

According to staging criteria of the TNM system, 21\% of patients (90 cases) were in stage I, 32.5\% (139 cases) in stage II, $46.5 \%$ (199 cases) in stage III.

At the time of surgery none of the patients presented distant metastases. Histopathological types of breast cancers included ductal carcinoma 64.7\% (277 cases), lobular carcinoma $23.1 \%$ (99 cases), and other types $12.1 \%$ (52 cases).

The CA 15-3 and CEA serum levels were available in records of the all patients in the study and CA 15-3 levels were in the normal range in $55.6 \%$ and elevated in $44.4 \%$, CEA levels were in the normal range in $52.8 \%$ and elevated in $47.2 \%(\mathrm{p}=\mathrm{NS})$.

Elevated CA15-3 levels were observed in $38.9 \%$ of stage I patients, $42.4 \%$ of stage II, and $46.2 \%$ of stage III patients $(\mathrm{p}=\mathrm{NS})$.

Elevated serum levels of CEA were observed in $47.8 \%$ of stage I patients, $48.2 \%$ of stage II and $46.2 \%$ of stage III patients ( $\mathrm{p}=\mathrm{NS}$ ).

In patients with ductal carcinoma, elevated serum levels of CEA and CA13-5 were observed in 48.7\% and $42.2 \%$ respectively. In the lobular type, the respective figures were $42.4 \%$ and $52.5 \%$, and in non-ductal/tubular types were $48.1 \%$ and $40.4 \%(p=N / S)$. Statistical analysis revealed a trend toward higher frequency of elevated CEA in patients with ductal carcinoma vs lobular type.

The presence of serum CEA and CA15-3 elevation in the patients with breast cancer divided into groups with respect to the stage of the disease was presented in Table 1. The occurrence of CEA and CA15-3 elevation in the patients with breast cancer divided into groups with respect to the histological type was shown in Table 2. The presence of serum CEA and CA15-3 elevation in the patients with breast cancer divided into group with ductal and non-ductal type of cancer is depicted in Table 3.

Logistic regression analysis revealed that ductal type of breast cancer was related to the elevated serum level of CEA (OR: 6.2 95\% CI $(2.1-18.4) \mathrm{p}<0,001)$. The elevated serum level of CA 15-3 was negatively
Table 1. The occurrence of CEA and CA15-3 elevation in the patients with breast cancer divided into groups according to the stage of the disease.

\begin{tabular}{|c|c|c|}
\hline Stage & Serum tumor markers & $\begin{array}{l}\text { No. of patients } \\
\text { (\% of the patients } \\
\text { within given group) }\end{array}$ \\
\hline$\underset{n=90}{I}$ & $\begin{array}{l}\text { both } C F \wedge(\uparrow) \text { and } C \wedge 15-3(\uparrow) \\
\text { only } C L A(\uparrow) \\
\text { only } C \wedge 15-3(\uparrow) \\
\text { none }\end{array}$ & $\begin{array}{l}45(50) \\
10(11.1) \\
2(2.2) \\
33(36.7)\end{array}$ \\
\hline $\begin{array}{c}\mathrm{Il} \\
\mathrm{n}=139\end{array}$ & $\begin{array}{l}\text { both } C F \wedge(\uparrow) \text { and } C \wedge 15-3(\uparrow) \\
\text { only } C E A(\uparrow) \\
\text { only } C \wedge 15-3(\uparrow) \\
\text { none }\end{array}$ & $\begin{array}{l}70(50.4) \\
10(7.2) \\
2(1.4) \\
57(41)\end{array}$ \\
\hline $\begin{array}{c}\text { III } \\
n=199\end{array}$ & $\begin{array}{l}\text { both CLA }(\uparrow) \text { and CA } 15-3(\uparrow) \\
\text { only CFA }(\uparrow) \\
\text { only CA } 15-3(\uparrow) \\
\text { none }\end{array}$ & $\begin{array}{l}101(50.7) \\
2(1) \\
6(3) \\
90(45.2)\end{array}$ \\
\hline
\end{tabular}

Table 2. The occurrence of CEA and CA15-3 elevation in the patients with breast cancer divided into groups according to the histological type.

\begin{tabular}{|c|c|c|}
\hline $\begin{array}{l}\text { Histological } \\
\text { type }\end{array}$ & $\begin{array}{l}\text { The level of serum tumor } \\
\text { markers }\end{array}$ & $\begin{array}{l}\text { No. of patients } \\
\text { (\% of patients } \\
\text { within given } \\
\text { group) }\end{array}$ \\
\hline $\begin{array}{l}\text { ductal } \\
\mathrm{n}=277\end{array}$ & $\begin{array}{l}\text { both CLA }(\uparrow) \text { and CA } 15-3(\uparrow) \\
\text { only CFA }(\uparrow) \\
\text { only CA } 15-3(\uparrow) \\
\text { none }\end{array}$ & $\begin{array}{l}142(51.3) \\
18(6.5) \\
0(0) \\
117(42,2)\end{array}$ \\
\hline $\begin{array}{l}\text { lobula } \\
\mathrm{n}=99\end{array}$ & $\begin{array}{l}\text { both CLA }(\uparrow) \text { and CA } 15-3(\uparrow) \\
\text { only CFA }(\uparrow) \\
\text { only CA } 15-3(\uparrow) \\
\text { none }\end{array}$ & $\begin{array}{l}47(47.5) \\
0(0) \\
10(10.1) \\
42(42.4)\end{array}$ \\
\hline $\begin{array}{l}\text { non-lobular, } \\
\text { non ductal } \\
\mathrm{n}=52\end{array}$ & $\begin{array}{l}\text { both CFA }(\uparrow) \text { and } C \wedge 15-3(\uparrow) \\
\text { only CLA }(\uparrow) \\
\text { only CA } 15-3(\uparrow) \\
\text { none }\end{array}$ & $\begin{array}{c}27(51.9) \\
4(7.7) \\
0(0) \\
21(40.4)\end{array}$ \\
\hline
\end{tabular}

Table 3. The presence of CEA and CA15-3 elevation in the patients with breast cancer divided into group with ductal and nonductal cancer group. The percentage of patients refers to the group according to histological type.

\begin{tabular}{|c|c|c|c|}
\hline $\begin{array}{l}\text { Ilistological } \\
\text { type }\end{array}$ & $\begin{array}{l}\text { The level of the } \\
\text { tumor marker }\end{array}$ & $\begin{array}{c}\text { Normal } \\
\text { CA 15-3 } \\
238 \\
(56.6 \%)\end{array}$ & $\begin{array}{c}\text { Flevated } \\
\text { CA 15-3 } \\
190 \\
(44.4 \%)\end{array}$ \\
\hline \multirow{2}{*}{$\begin{array}{l}\text { ductal } \\
277(64.7 \%)\end{array}$} & Normal CFA & $142(51.2)$ & $0(0)$ \\
\hline & Flevated CF $\Lambda$ & $18(6.5)$ & $117(42.2)$ \\
\hline \multirow{2}{*}{$\begin{array}{l}\text { non ductal } \\
151(35.3 \%)\end{array}$} & Normal CLA & $74(49.0)$ & $10(6.6)$ \\
\hline & Llevaled CLA & $4(2.6)$ & $63(41.7)$ \\
\hline
\end{tabular}

related to the occurrence of ductal cancer (OR: 0.16, $95 \%$ CI $(0.05-0.46) \mathrm{p}<0.001)$ and the stage of the disease was not related to the ductal type. 


\section{Discussion}

CEA and CA 15-3 are the most widely used serum markers in breast cancer. The occurrence of elevated levels of these tumour markers are similar to those observed in other studies and confirm their low sensitivity for early breast cancer [8].

The main finding of our study was lack of relationship between the elevation of the serum level of breast cancer tumour markers CEA and CA 15-3 and the cancer histological type. The logistic regression analysis allowed to show that the presence of ductal type of breast cancer was related with the normal serum level of CA 15-3 and elevated serum level of CEA. Indeed, normal levels of CA 15-3 and elevated levels of CEA were present in $6.5 \%$ of patients with ductal type and only in $2.6 \%$ of patients with non-ductal type thus the ratio of the patients fulfilling this criterion in the former group is nearly 3 times higher than in the later, however low absolute numbers of these patients reduced the clinical importance of this finding. Our results are concordant with the results of other authors who have shown that serum CEA was present in each histological type of the breast tumours and in the invasive ductal tumors it was slightly higher than in the lobular ones [9]. Different histological types of breast cancer have similar propensity to produce increased amount of serum CEA and CA 15-3 although the immunohistochemical tests revealed that in ductal tumors more cancer cells stain for CEA than in other breast cancers [10]. Oncogenic mechanisms may be heterogenic in breast ductal and lobular epithelium but these two origins of breast cancer are not considerably different with respect to the increased serum level of CEA and CA 15-3.

The second finding was the lack of significant dependence of the disease stage and the occurrence of elevated levels of CEA and CA 15-3. The results of other authors regarding the relationship between diseases stage and the level of tumour markers are discordant. Some authors have reported more frequent occurrence of the elevated plasma levels of these tumour markers in more advance stages of that disease but others have reported lack of statistical relation between serum levels of these markers with disease stage [11]. Moreover the preoperative serum CA 15-3 level is useless for determining the histologic grade of the tumor [3]. The differences between studies may depend on the clinical characteristics of the studied group. The relation between disease stage and the presence of the elevation of CEA and CA 15-3 levels is more obvious in studies performed on the unselected patients with breast cancer with the subgroup of patients with metastases. Our group was preselected as only the surgical patients were included.

CA 15-3 is used for surveillance and monitoring of therapy in patients with breast cancer, however even in advanced stage disease its levels may remain within normal range $[12,13]$. In these circumstances it is recommended to consider testing other tumour markers for the monitoring purposes. Our results indicate low significance of the CEA serum level for this purpose as only about $10 \%$ of patients with normal level of CA 15-3 had elevated CEA serum concentration. Similar results for both markers (either both negative or both positive) was observed in $92 \%$ of cases whereas only in $8 \%$ of the patients one of the studied markers is elevated whereas the second was within normal values. That indicated low efficacy of the method of tumour marker analysis relying on measurement of CEA serum level when CA 15-3 is within normal range. Other authors have also reported that analysis of CEA serum level along with that of CA 15.3, rather than the latter alone added only a $6 \%$ to its sensitivity in overall population [14]. The histological types of breast cancer are not significantly related with the presence of the elevated serum levels of CEA and /or CA 15-3. The elevated level of CEA and normal level of CA 153 significantly indicate ductal cancer although this configuration of tumor marker levels is not common. In the studied population most of patients had concordant (either elevated or both normal) levels of CEA and CA 15-3 thus the examination of CEA when CA $15-3$ is within normal values yields only a small increase in sensitivity. The presence of elevated serum levels of CEA and CA 15-3 was not significantly related with the stage of the disease according to TNM classification in the group of breast cancer patients referred for breast surgery.

\section{References}

[ 1] Lindblom A, Liljegren A. Tumour markers in malignancies. Clin Rev. 2000;320:424-427.

[2] Molina R, Barak V, van Dalen A. et al. Tumor markers in breast cancer- European Group on Tumor Markers recommendations. Tumour Biol. 2005;26:281-93.

[ 3] Seker D, Kaya O, Adabag A et al. Role of preoperative plasma $\mathrm{Ca} 15.3$ and carcinoembryonic antygen levels in determining histopathologic conventional prognostic factors for breast cancer. World J Surg. 2003;27:519-521.

[4] Duffy MJ. Serum tumor markers in breast cancer: are they of clinical value? Clin Chem. 2006;52:345-51.

[ 5] Al-azawi D, Kelly G, Myers E. et al. CA 15-3 is predictive of response and disease recurrence following treatment in locally advanced breast cancer. BMC Cancer. 2006;6:220.

[ 6] Dnistrian AM, Schwartz MK, Greenberg EJ et al. Ca 15.3 and carcinoembryonic antigenin the clinical evaluation of breast cancer. Clin Chim Acta. 1991;200:81-93.

[ 7 ] World Health Organisation. International Classification of Diseases. 10 $0^{\text {th }}$ Ed. Geneva; 1998.

[ 8] Kermani IA. Variation of tumor markers in 277 breast cancer cases. Asian Pac J Cancer Prev. 2004;5(3):291-3.

[9] Stratil P, Rejthar A, Lang BA et al. Occurrence of carcinoembryonic antigen in tumor tissue and serum of breast cancer patients. Neoplasma. 1988;35:69-76.

[10] Böcker W, Schweikhart G, Pollow K et al. Immunohistochemical demonstration of carcinoembryonic antigen (CEA) 
in 120 mammary carcinomas and its correlation with tumor type, grading, staging plasma-CEA, and biochemical receptor status. Pathol Res Pract. 1985;180:490-7.

[11] Park BW, Oh JW, Kim JH et al. Preoperative CA 15-3 and CEA serum levels as predictor for breast cancer outcomes. Ann Oncol. 2008;19:675-81.

[12] Harris L, Frische H, Mennel R et al. American Society of Clinical Oncology 2007 update of recommendations for the use of tumor markers in breast cancer. Clinical practice guidelines of American Society of Clinical Oncology. J Clin Oncol. 2007;25:5287-5312.
[13] Ebeling FG, Stieber P, Untch M et al. Serum CEA and Ca 15.3 as prognostic factors in primary breast cancer. Brit J Cancer. 2002;86:1217-1222.

[14] Guadagni F, Ferroni P, Carlini S et al. A re-evaluation of carcinoembryonic antigen (CEA) as a serum marker for breast cancer: a prospective longitudinal study. Clin Cancer Res. 2001;7:2357-62.

Submitted: 10 October, 2009 Accepted after reviews: 21 December, 2009 